\title{
MOTIVES AND MOTIVATING LEADERS IN AEROBICS CLASSES: EXERCISE MOTIVATION AND INSTRUCTORS' LEADERSHIP CHARACTERISTICS
}

\author{
A. Hannus, M. Laev \\ Institute of Sport Pedagogy and Coaching Science, \\ University of Tartu, Tartu, Estonia
}

\begin{abstract}
The aim of this study was to investigate the motives of aerobics participants in relation to their perceived and preferred leadership behavior of aerobic instructors.

Eighty seven aerobics participants (aged between 16-59 y) completed the cross-sectional questionnaire survey. Instruments assessed participants' exercise motivation, and perceived and preferred leadership behaviour of their aerobic instructors.

We found that in aerobics participants the appearance- and healthrelated dimensions of exercise motivation are higher ranked than flexibility and social motives. Although aerobics participants show relatively high levels of competitive and social motives compared with general population, the highest ranked incentive for them seems to be physical fitness. Aerobics participants perceive significantly less instructors' democratic decision making, instruction, social support and positive feedback than they prefer, while they perceive significantly higher amount of autocratic decision making compared with their preference.
\end{abstract}

Key words: motivation for participation in aerobics, leadership behavior 


\section{INTRODUCTION}

Since more than three decades motivation for fitness activities and factors which influence exercise participation have been a matter of special interest to researchers. Most frequently motives such as enjoyment, social interaction, positive affective responses and perceived accomplishment have emerged [5]. The aim of the present study was to investigate the role of various motivating factors in participation in aerobics. Aerobics was chosen as it provides an exercise context including personal goals in a group setting, potentially reflecting both individual and social motivational factors.

Participation motives represent diverse goals for taking part in a particular domain of behaviour. Often motivation for participation in both sport and exercise has been explained in terms of the SelfDetermination Theory (SDT) $[8,9]$. According to the SDT, the regulation towards exercise participation can be amotivated, extrinsically motivated or intrinsically motivated. Research reveals that intrinsic motivation represents autonomous behavioural regulation which is associated with greater continuous participation in physical activity $[11,12,21]$. In general, intrinsic motivation reflects engaging in the activity for its own sake. An intrinsically motivated person considers the physical activity inherently enjoyable, interesting, and challenging $[8,9]$. Still, findings are less clear in aerobics setting. Frederick and Shaw [10] found that appearance-related motives dominate in aerobics participation. Importantly, Laverie [15] determined 6 distinctive motives for participation in aerobics: atmosphere of an aerobics class, physical and psychological benefits, social ties related to aerobics, social comparisons, obsession with aerobics, and feelings associated with doing aerobics.

In sport settings, besides motivational characteristics, specific coaching behaviors also have the potential to influence cognitive and behavioral processes in athletes $[5,6]$. Over the past decades the most extensively studied framework for explanation of coaches' leader behavior is the Multidimensional Model of Leadership (MML) [4]. This model proposes that leader behavior can influence group performance and member satisfaction. Specifically, it suggests that three aspects of leader behavior need to be in congruence to achieve effective group performance and member satisfaction. First, required behavior (what is needed for a particular situation) is prescribed by situational and member characteristics such as goals, structure, group 
task, norms etc. Second, preferred behavior (expected by the athletes) originates from both situational and member characteristics, e.g. goals, abilities, personality, and attitudes toward authority. Third, perceived behavior (the coach's behavior as perceived by the athletes) is determined by the characteristics of the leader (personality, ability, experience, and decision making style), but also by required and preferred leader behavior. The leader, as suggested by the MML, may alter his or her behavior to the requirements of the situation and the preferences of the members in order to increase congruence between those three aspects of leadership behavior.

There is evidence that smaller discrepancy between perceived and preferred leadership behavior has a significant positive effect on motivation [1]. Particularly, more frequent training and instructional guidance and infrequent use of autocratic decision style increase the satisfaction of members. Also, it has been found that most of leader behavior has a positive impact on member satisfaction if preferred and perceived leader behavior is concordant $[2,19]$. However, a recent study in Estonia demonstrated that individual athletes perceive less training and instruction, democratic decision making, social support, and positive feedback from their coaches than they prefer. In contrast, they reported higher amount of perceived autocratic decision making compared to what they prefer [20].

Although there is a large body of research in exercise motivation, only a few studies have been conducted to explore (motivational) features of exercise instructor's behaviour. It has been found that intrinsic motivation and supportive leadership have motivating effect on women's exercises participation [16]. Similarly, in female exercisers socially enriched leadership is associated with greater exercise enjoyment [3]. In Estonia, aerobics participants have demonstrated higher intrinsic motivation compared with gym and indoor rowing participants [14], while instructional and motivational behavior of instructor is positively related to intrinsic motivation [17].

In this study we explored exercise motives for participation in aerobics. First, we assessed exercise motives of aerobics participants and compared them with exercise motives in a representative Estonian female sample. Second, in order to find which exercise motives are more salient than others in aerobics participants, we estimated relative weight of distinctive exercise motives. Third, we assessed perceptions and preferences for instructor's leadership behavior and their relations to exercise motives in aerobics participants. 


\section{MATERIALS AND METHODS}

\section{Participants and procedure}

Data were collected from cross-sectional survey in 7 exercise clubs. Inclusion criterion for volunteers was participation in a formal aerobics exercise group lead by an instructor. One of the authors distributed the questionnaires personally to each participant and explained the general purpose of the study. Participants returned the completed questionnaires within 2 weeks.

Out of 272 delivered questionnaires 94 (34.6\%) were returned. Due to missing values 7 questionnaires were omitted from analysis. Therefore, data from 87 aerobics participants (aged between 1659 years, mean $=26.1, \mathrm{SD}=9.0$ ) were included in the study.

\section{Measures}

To measure characteristics of personal exercise motives and instructor's leadership behaviour, following questionnaires were used:

1. Modified Estonian Exercise Motivation Questionnaire-2, (EMQ2EM [18]; [original 13]). EMQ-2M consists of 37 items. Subscale scores were computed for 7 different exercise motives: Competition (e.g. I exercise to compare my abilities with other peoples'), Health (I exercise because I want to maintain good health), Appearance (I exercise to improve my appearance), Social Recognition (I exercise to have fun being active with other people), Fun and Relaxation (I exercise because I find exercising satisfying in and of itself), Physical Fitness (I exercise to build up my strength), and Flexibility (I exercise to stay/become flexible). The response format was to indicate how much each statement is true for the participant from not at all true for me (0) to very true for me (5).

2. Estonian Leadership Scale for Sport (E-LSS [20]; [original 7]). LSS is a sport-specific questionnaire designed to assess 5 distinctive dimensions of leadership behaviour. Specifically, LSS is designed to assess (a) perceived leadership behaviour and (b) preferred leadership behaviour.

2.1. The Perceived Leadership Behaviour (PercLB) form requires participants to estimate the frequency (never, seldom, occasionally, often, always) of specific behaviours. Forty items represent the 5 subscales: Training and Instruction (My coach instructs every person individually in the skills of the sport), Democratic Behaviour (My 
coach lets the group set its own goals), Autocratic Bahaviour (My coach speaks in a manner not to be questioned), Social Support (My coach does personal favors for the exercisers), and Positive Feedback (My coach compliments a person for her performance in front of others).

2.2. The Preferred Leadership Behavior (PrefLB) form requires indicating to what extend the participant prefers to experience those five behaviors.

\section{Statistical analysis}

Statistical analyses were performed using the STATISTICA (version 8.0) software. Results are expressed as mean values (mean), standard deviations (SD), and sample size $(\mathrm{N})$. The one-sample t-tests and Student's t-test were performed to contrast mean values. Pearson's correlation coefficients indicate connections between variables. An alpha level of .05 was used for all statistical tests.

To compare the exercise motives of aerobics participants with the exercise motives of a representative Estonian female sample, the subscale scores of the EMI-2EM were standardized by adding up the raw scores of each subscale, then dividing this sum by the number of items in that subscale, and multiplying it by five [18].

\section{RESULTS}

\section{Descriptive statistics}

Table 1 and 2 represent the descriptive statistics of EMI-2EM, PercLB, and PrefLBH. First, the exercise motives of aerobic participants were compared with the respective motives of a representative Estonian female sample consisting of 931 females between 18 and 55 years [18]. To illustrate the exercise motives of aerobics participants in relation to Estonian female sample, the T-scores were calculated (Table 1). 
Table 1. Descriptive statistics of Modified Estonian Exercise Motivation Questionnaire-2 and the T-score values of aerobics participants in relation to Estonian female sample $(\mathrm{n}=87)$.

\begin{tabular}{|l|c|c|c|}
\hline Subscale & mean & SD & T-score \\
\hline Competition & 9.36 & 4.9 & 58.2 \\
\hline Health & 19.23 & 4.5 & 59.8 \\
\hline Appearance & 18.19 & 6.6 & 83.2 \\
\hline Social Recognition & 8.68 & 6.3 & 74.4 \\
\hline Fun \& Relaxation & 18.48 & 4.9 & 62.8 \\
\hline Physical Fitness & 20.01 & 4.5 & 73.0 \\
\hline Flexibility & 15.90 & 6.8 & 72.3 \\
\hline
\end{tabular}

$\mathrm{T}$-scores are calculated in relation to the representative Estonian female sample $n=931$ by Matsi [18].

Table 2. Descriptive statistics of the Perceived Leadership Behavior (PercLB) and Preferred Leadership Behavior (PrefLB) (n=87).

\begin{tabular}{|l|c|c|c|c|}
\hline & \multicolumn{2}{|c|}{ PercLB } & \multicolumn{2}{c|}{ PrefLB } \\
\hline Subscale & mean & SD & mean & SD \\
\hline $\begin{array}{l}\text { Training and } \\
\text { Instruction }\end{array}$ & 3.39 & 0.7 & 3.62 & 0.6 \\
\hline $\begin{array}{l}\text { Democratic } \\
\text { Behaviour }\end{array}$ & 3.18 & 0.6 & 3.33 & 0.6 \\
\hline $\begin{array}{l}\text { Autocratic } \\
\text { Behaviour }\end{array}$ & 2.00 & 0.6 & 1.86 & 0.5 \\
\hline Social Support & 2.22 & 0.5 & 2.34 & 0.5 \\
\hline Positive Feedback & 3.20 & 0.9 & 3.33 & 0.8 \\
\hline
\end{tabular}

Further, one sample t-tests indicated motivational deviation of aerobics participants from Estonian female sample. We found that aerobics participants showed significantly higher Competition motive (9.36 \pm 4.9) compared with the Estonian female sample (5.31 \pm 5.4$), \mathrm{t}[1016]=$ $6.68, \mathrm{p}<.00001$. The same effect was found for Fun and Relaxation

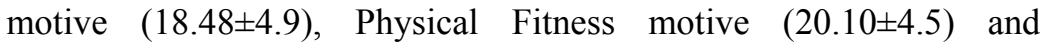
Flexibility motive $(15.90 \pm 6.8)$ compared with the Estonian female sample $(15.18 \pm 5.7), \mathrm{t}[1016]=4.53, \mathrm{p}<0.0001 ; 15.00 \pm 6.7 ; \mathrm{t}[1016]=$ $6.80, \quad \mathrm{p}<0.00001 ;$ and $(12.46 \pm 8.09), \mathrm{t}[1016]=5.06, \quad \mathrm{p}<0.00001$, respectively. 


\section{Relative saliency of exercise motives}

In order to assess the relative saliency of distinctive exercise motives, $\mathrm{t}$-tests were conducted. Table 3 represents the $t$-statistics illustrating differences in mean scores of exercise motives. In general, Competition and Social Recognition motives showed the lowest mean scores in aerobics participants (see Table 3 ).

Table 3. Comparision of the mean scores of exercise motives (EMI2EM). Differences between the mean values are represented as $t$-scores, $\mathrm{t}(86)(\mathrm{n}=87)$.

\begin{tabular}{|c|c|c|c|c|c|c|}
\hline & Health & $\begin{array}{l}\text { Appea- } \\
\text { rance }\end{array}$ & $\begin{array}{c}\text { Social } \\
\text { Re- } \\
\text { cognition }\end{array}$ & $\begin{array}{c}\text { Fun \& } \\
\text { Re- } \\
\text { laxation }\end{array}$ & $\begin{array}{c}\text { Physical } \\
\text { Fitness }\end{array}$ & $\begin{array}{l}\text { Flexibi- } \\
\text { lity }\end{array}$ \\
\hline $\begin{array}{l}\begin{array}{l}\text { Subscale } \\
\text { (mean) }\end{array} \\
\end{array}$ & $(\mathbf{1 9 . 2 )}$ & (18.2) & (8.7) & (18.5) & (20.0) & $(\mathbf{1 5 . 9 )}$ \\
\hline $\begin{array}{l}\text { Competition } \\
(9.4)\end{array}$ & $15.71 \% *$ & $11.09^{* *}$ & 1.01 & $15.62 * *$ & $20.89 * *$ & $8.59 * *$ \\
\hline Health & & 1.29 & $13.72 * *$ & 1.37 & 1.49 & $4.54 * *$ \\
\hline Appearance & & & $10.60 * *$ & 0.34 & 2.24 & 2.20 \\
\hline $\begin{array}{l}\text { Social } \\
\text { Recognition }\end{array}$ & & & & $14.75^{* *}$ & $15.16 * *$ & $7.66^{* * *}$ \\
\hline $\begin{array}{l}\text { Fun \& } \\
\text { Relaxation }\end{array}$ & & & & & 2.60 & 3.28* \\
\hline $\begin{array}{l}\text { Physical } \\
\text { Fitness }\end{array}$ & & & & & & $6.47 * *$ \\
\hline
\end{tabular}

Statistically significant $t$-statistics are printed in bold $\mathrm{p}<0.05,{ }^{*} \mathrm{p}<0.01$, $* * \mathrm{p}<0.001$.

Next, we divided the sample into two subgroups based on the score of Fun and Relaxation motive. The aim was to search for further explanations for higher levels of exercise motivation in comparison to the representative Estonian sample. The rationale behind this was to differentiate participants based on the exercise motive potentially highly representative for intrinsic motivation. The cut-off score was 3.5 points. Group differences between low and high Fun and Relaxation motive groups are presented in Table 4. 
Tabel 4. Comparison of exercise motives between subgroups characterized by low $(<3.5)$ and high $(\geq 3.5)$ Fun and Relaxation motive.

\begin{tabular}{|l|c|c|c|c|c|c|}
\hline & \multicolumn{2}{|c|}{ Low F\&R } & \multicolumn{2}{c|}{ High F\&R } & & \\
\hline Subscale & mean & SD & mean & SD & t & p \\
\hline Competition & $\mathbf{1 . 3 9}$ & $\mathbf{0 . 8}$ & $\mathbf{2 . 1 3}$ & $\mathbf{1 . 0}$ & $\mathbf{3 . 5 4 1}$ & $\mathbf{0 . 0 0 0 6 5 0}$ \\
\hline Health & $\mathbf{3 . 4 3}$ & $\mathbf{1 . 0}$ & $\mathbf{4 . 0 6}$ & $\mathbf{0 . 8}$ & $\mathbf{3 . 2 4 5}$ & $\mathbf{0 . 0 0 1 6 8 3}$ \\
\hline Appearance & 3.54 & 1.2 & 3.69 & 1.4 & 0.504 & 0.615545 \\
\hline $\begin{array}{l}\text { Social } \\
\text { Recognition }\end{array}$ & $\mathbf{1 . 2 6}$ & $\mathbf{1 . 2}$ & $\mathbf{1 . 9 9}$ & $\mathbf{1 . 2}$ & $\mathbf{2 . 6 8 3}$ & $\mathbf{0 . 0 0 8 7 6 1}$ \\
\hline $\begin{array}{l}\text { Physical } \\
\text { Fitness }\end{array}$ & $\mathbf{3 . 6 4}$ & $\mathbf{1 . 1}$ & $\mathbf{4 . 2 0}$ & $\mathbf{0 . 7}$ & $\mathbf{2 . 8 6 6}$ & $\mathbf{0 . 0 0 5 2 4 2}$ \\
\hline Flexibility & 2.81 & 1.4 & 3.37 & 1.3 & 1.819 & 0.072469 \\
\hline
\end{tabular}

Low F\&R - subgroup of participants low in Fun and Relaxation motive, $\mathrm{n}=30$ (Fun and Relaxation mean $=2.55, \mathrm{SD}=1.4$ ), High $\mathrm{F} \& \mathrm{R}-$ subgroup of participants high in Fun and Relaxation motive, $\mathrm{n}=57$ (Fun and Relaxation mean $=4.30, \mathrm{SD}=1.8$ ); $\mathrm{t}$ statistics and Alpha values are presented.

\section{Relations between instructor's leadership behavior and exercise motives}

Correlation analysis estimated relationships between perceived or performed leadership behavior of aerobics instructors and exercise motives. Interestingly, Competition motive was negatively related to both perceived Democratic and Autocratic Behavior $(\mathrm{r}=-0.22, \mathrm{p}<0.05)$ while it was positively related to preferred Democratic $(\mathrm{r}=0.21$, $\mathrm{p}<0.05)$ and Autocratic Behavior $(\mathrm{r}=0.32, \mathrm{p}<0.05)$. In addition, participants higher in Physical Fitness motive perceived less Positive Feedback from instructors $(r=0.22, p<0.05)$. Further, higher Flexibility motive was related to lower frequency of perceived Autocratic Behavior $(\mathrm{r}=0.21, \mathrm{p}<0.05)$ and higher preferred Autocratic Behavior $(\mathrm{r}=0.26, \mathrm{p}<0.05)$. Individuals with higher Appearance motive would prefer to get more Training and Instruction $(\mathrm{r} 0=0.29)$ and Democratic Behavior $(\mathrm{r} 0=0.22, \mathrm{p}<0.05)$ from their instructors.

\section{Congruence between perceived and preferred leadership behavior in aerobic instructors}

Finally, we were interested in congruence between perceived and preferred leadership behavior of aerobics instructors. In order to estimate potential discrepancies we calculated proportional difference 
between perceived and preferred behavior. Specifically, we calculated ratios of perceived behavior to preferred behavior (Figure 1). Results indicated that participants perceived more Autocratic Behavior than preferred $(110.6 \%)$. In contrast, participants reported less perceived Training and Instruction (94.3\%), Democratic Behavior (97.0\%), Social Support (96.2\%), and Positive Feedback (98.7\%) in relation to preferred leadership behaviors. However, t-tests for single sample suggest that discrepancies were statistically significant only for Training and Instruction $(\mathrm{t}[86]=-3.77, \mathrm{p}<0.001)$ and Autocratic Behavior $(\mathrm{t}[86]=3.39, \mathrm{p}<0.01)$.

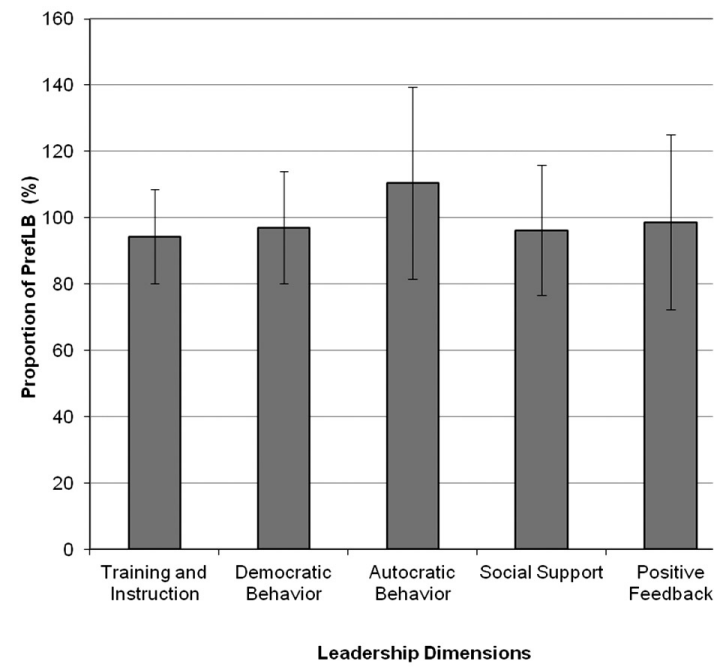

Figure 1. Congruence between perceived and preferred leadership behavior of aerobics instructors presented as proportional difference between perceived and preferred behavior (ratios of perceived behavior over preferred behavior). Mean values and standard deviations are presented.

\section{DISCUSSION}

In this study we first aimed to explore exercise motives of individuals regularly participating in aerobics classes. Secondly, we estimated how aerobics participants perceive the behavior of their instructors 
and how they would prefer instructors to behave. Thirdly, we were interested in relations between motives for aerobics participation, specific leadership behaviors demonstrated by aerobics instructors and preferences for instructor's behavior.

Previous studies in samples of aerobics exercisers reveal rather controversial results $[3,10,14,15,17]$. Therefore we decided to compare a female sample of aerobics exercisers to a relatively large representative sample of Estonian females and to estimate the saliency of distinctive motives. Our results suggest that aerobics exercisers show higher levels of enjoyment related motives as well as motives related to competing and social evaluation, and increasing one's physical fitness, compared to the general female population. However, individuals regularly participating in aerobics classes rate fitness- and health-related motives significantly higher than competitive and social motives. Fun and Relaxation motive, reflecting enjoyment of exercise, shows the third-highest rank for aerobics participants.

We propose that these results could be interpreted in terms of enjoyment of exercising. About $2 / 3$ of our participants demonstrated rather high level of fun and relaxation motive. Previous results in the general Estonian female population (including sedentary individuals) suggest that only fun and relaxation motive is systematically related to actual physical activity [18]. In current study we found most exercise motives to be elevated in the subgroup of high level fun and relaxation motive, compared with subgroup of low fun and relaxation motivation. In terms of the SDT we propose that fun and relaxation motives reflect enjoyment of exercise. Experience of fun and enjoyment represent intrinsic motivation, which is a strong predictor of regular physical activity $[11,12,21]$. A rough suggested explanation would be that strong intrinsic regulation supports also high levels of motives related to social comparison and social recognition. These motives could easily align with intrinsic need for relatedness [8,9]. Physical fitness motive (also higher in the subgroup of high fun and relaxation motivation) might derive from the intrinsic need for perceived competence. In contrast, the appearance motive which definitely reflects extrinsic motivation did not differentiate between the subgroups of high and low fun and relaxation motivation. Thus, although aerobics participants show relatively high levels of competitive and social motives compared with general population, the highest ranked incentive for them seems to be physical fitness. We suggest that in 
future studies the role of intrinsic motivation should be carefully investigated in aerobics settings.

Although we found that aerobic exercisers are driven by motive to compete more frequently than general population, this motive is relatively low in comparison with most other motives in the sample of aerobics participants. Most likely, this reflects the nature of aerobics classes, where no explicit competition occurs. Highly competitive individuals probably seek to participate in competitive sports. This explanation is supported by the fact that we found no systematic relationship between fun and relaxation motive and competition motive. Notably, the motive of physical fitness was not only higher in aerobic exercisers than in the rest of the population, but it appeared also to be the highest ranked exercise motive in aerobic participants.

Our findings also shed light on the perception and preference of instructors' leadership behavior. We found a negative relationship between competitive motive and both perceived autocratic and democratic behaviour. Thus, individuals higher in competitive motive report their aerobics instructors to show less democratic and autocratic decision making during exercise classes. In addition, since competitive motivation was positively related to prefer democratic and autocratic decision making, it seems that more competitive individuals would prefer their instructors to ask explicitly for participants' opinion and/or make more resolute decisions. Furthermore, discrepancies between the amount of perceived and preferred leadership behaviors indicate that aerobics exercisers with high competitive motive perceive less decision making behaviors than they would prefer experience in their exercise classes.

Generally, we can conclude that high levels of exercise motives predominantly reflecting intrinsic behavior regulation differentiate aerobics exercisers from general population. Exercise motives are systematically related to perceived and preferred leadership behavior of aerobics instructors. Further empirical research is required to find causal relationships between exercise motives and leadership behaviors that support exercise motivation. 


\section{REFERENCES}

1. Amorose A. J., Horn, D. S. (2000) Intrinsic motivation: Relationships with collegiate athletes gender, scholarship status and perceptions of their coaches behavior. J. Sport Exerc. Psychol. 22: 63-84

2. Andrew D. (2009) The impact of leadership behavior on satisfaction of college tennis payers: a test of the leadership behavior congruency hypothesis of the Multidimensional Model of Leadership. J. Sport Behav. 32: 261-277

3. Bray S. R., Millen J. A., Eidsness J., Leuzinger, C. (2005) The effects of leadership style and exercise program choreography on enjoyment and intentions to exercise. Psychol. Sport Exerc. 6: 415-425

4. Chelladurai P. (1978) A contingency model of leadership in athletics. Unpublished doctoral dissertation. Department of Management Sciences, University of Waterloo, Canada

5. Chelladurai P. (1990) Leadership in sports: A review. Int. J. Sport Psychol. 21: 328-354

6. Chelladurai P. (1993) Leadership. In: Handbook on research on sport psychology, R. N. Singer, M. Murphy, L. K. Tennant (eds). New York: McMillan. 647-671

7. Chelladurai P., Saleh S. D. (1980) Dimensions of leader behavior in sports. Can. J. Appl. Sport Sci. 3: 85-92

8. Deci E. L., Ryan R. M. (1985) Intrinsic motivation and selfdetermination in human behaviour. New York: Plenum Press

9. Deci E. L., Ryan R. M. (2000) The "what" and "why" of goal pursuits: Human needs and the self-determination of behavior. Psychol. Inquiry. 11: 227-268

10. Frederick C. J., Shaw S. M. (1995) Body image as a leisure constraint. Examining the experience of aerobic exercise classes for young women. Leisure Sci. 17: 57-73

11. Gillison F. B., Standage M., Skevington S. M. (2006) Relationships among adolescents' weight perceptions, exercise goals, exercise motivation, quality of life and leisure-time exercise behaviour: a selfdetermination theory approach. Health Educ. Res. 21: 836-847

12. Ingledew D. K., Markland D. (2008) The role of motives in exercise participation. Psychol. Health. 23: 807-828

13. Ingledew D., Markland D., Medley A. (1998) Exercise Motives and Stages of Change. J. Health Psychol. 3: 477-489

14. Klaos, H. (2007) Harrastussportlase motivatsioon, enese-esitlemine ja psühholoogilised vajadused. Unpublished master thesis. Faculty of Sport and Exercise Sciences, University of Tartu, Estonia 
15. Laverie D. (1998) Motivation for ongoing participation in a fitness activity. Leisure Sci. 20: 277-303

16. Lloyd K. M., Little D. E. (2010) Keeping women active: An examination of the impacts of self-efficacy, intrinsic motivation, and leadership on women's persistence in physical activity. Women Health. 50: 652-669

17. Lukner K. (2007) Aeroobikaharrastajate treeningumotivatsioon ja hinnang treeneri käitumisele. Unpublished master thesis. Faculty of Sport and Exercise Sciences, University of Tartu, Estonia

18. Matsi J. (2009) Eesti 18-50 aastaste naiste enese raporteeritud vaba aja kehalise aktiivsuse motivatsioon ja takistused. Unpublished master thesis. Institute of Psychology, University of Tartu, Estonia

19. Riemer H. A., Chelladurai P. (1995) Leadership and Satisfaction in Athletics. J. Sport Exerc. Psychol. 17: 276-293

20. Sirge K. (2008) Spordi Eestvedamise Küsimustiku adapteerimine Eesti individuaalsportlaste ja treenerite valimil. Unpublished master thesis. Faculty of Sport and Exercise Sciences, University of Tartu, Estonia

21. Standage M., Sebire S. J., Loney T. (2008) Does exercise motivation predict engagement in objectively assessed bouts of moderateintensity exercise?: a Self-Determination Theory perspective. J. Sport Exerc. Psychol. 30: 337-352

\section{Correspondece to:}

Aave Hannus

Institute of Sport Pedagogy and Coaching Science

University of Tartu

Ravila 14a, 50411 Tartu

Estonia

E-mail: aave.hannus@ut.ee 